University of Texas at El Paso

ScholarWorks@UTEP

\title{
$3-2018$
}

\section{How to Explain the Results of the Richard Thaler's 1997 Financial Times Contest}

Olga Kosheleva

The University of Texas at El Paso, olgak@utep.edu

Vladik Kreinovich

The University of Texas at El Paso, vladik@utep.edu

Follow this and additional works at: https://scholarworks.utep.edu/cs_techrep

Part of the Mathematics Commons

Comments:

Technical Report: UTEP-CS-18-21

\section{Recommended Citation}

Kosheleva, Olga and Kreinovich, Vladik, "How to Explain the Results of the Richard Thaler's 1997 Financial Times Contest" (2018). Departmental Technical Reports (CS). 1197.

https://scholarworks.utep.edu/cs_techrep/1197

This Article is brought to you for free and open access by the Computer Science at ScholarWorks@UTEP. It has been accepted for inclusion in Departmental Technical Reports (CS) by an authorized administrator of ScholarWorks@UTEP. For more information, please contact Iweber@utep.edu. 


\title{
How to Explain the Results of the Richard Thaler's 1997 Financial Times Contest
}

\author{
Olga Kosheleva ${ }^{1}$ and Vladik Kreinovich ${ }^{2}$ \\ ${ }^{1}$ Department of Teacher Education \\ ${ }^{2}$ Department of Computer Science \\ University of Texas at El Paso \\ 500 W. University \\ El Paso, TX 79968, USA \\ olgak@utep.edu,vladik@utep.edu
}

\begin{abstract}
In 1997, by using a letter published in Financial Times, Richard H. Thaler, the 2017 Nobel Prize winner in Economics, performed the following experiment: he asked readers to submit numbers from 0 to 100 , so that the person whose number is the closest to $\frac{2}{3}$ of the average will be the winner. An intuitive answer is to submit $\frac{2}{3}$ of the average (50), i.e., $33 \frac{1}{3}$. A logical answer, as can be explained, is to submit 0 . The actual winning submission was - depending on how we count -12 or 13 . In this paper, we propose a possible explanation for this empirical result.
\end{abstract}

\section{An Empirical Fact that Needs to be Explained}

Experiment. In 1997, Richard H. Thaler, the 2017 winner of Nobel Prize in Economics, performed the following experiment. In a letter to Financial Times, he asked the readers to submit numbers from 0 to 100 . The reader whose submission is the closest to $\frac{2}{3}$ of the average would be the winner; see, e.g., $[1,2]$.

Analysis of the problem: intuitive level. On the intuitive level, we expect numbers to be randomly distributed between 0 and 100, so the average should be 50 . Thus, it seems reasonable to submit $\frac{2}{3}$ of 50 , i.e.,

$$
\frac{2}{3} \cdot 50=33 \frac{1}{3}
$$

as an answer. 
Analysis of the problem: detailed logical analysis. While as a first approximation, the above answer may sound reasonable, in reality, we can go further. If everyone follows the above logic, then everyone would submit the same number $33 \frac{1}{3}$. Thus, the average would be $33 \frac{1}{3}$, and so, $\frac{2}{3}$ of this average would be

$$
\frac{2}{3} \cdot 33 \frac{1}{3}=\frac{2}{3} \cdot\left(\frac{2}{3} \cdot 50\right)=\left(\frac{2}{3}\right)^{2} \cdot 50=22 \frac{2}{9} .
$$

Now, it looks like it is reasonable for everyone to submit $22 \frac{2}{9}$, so the average is $22 \frac{2}{9}$, and it make sense to submit $\frac{2}{3}$ of this value, i.e., the value

$$
\frac{2}{3} \cdot 22 \frac{2}{9}=\frac{2}{3} \cdot\left(\left(\frac{2}{3}\right)^{2} \cdot 50\right)=\left(\frac{2}{3}\right)^{3} \cdot 50
$$

By the same logic, everyone should submit the value

$$
\left(\frac{2}{3}\right)^{3} \cdot 50
$$

Thus, this number would be the average, and so, the winning number would be $\frac{2}{3}$ of this average, i.e.,

$$
\frac{2}{3} \cdot\left(\left(\frac{2}{3}\right)^{3} \cdot 50\right)=\left(\frac{2}{3}\right)^{4} \cdot 50 .
$$

By the same logic, we need to guess $\frac{2}{3}$ of this number, i.e.,

$$
\frac{2}{3} \cdot\left(\left(\frac{2}{3}\right)^{4} \cdot 50\right)=\left(\frac{2}{3}\right)^{5} \cdot 50 .
$$

The same reasoning leads to the guess

$$
\left(\frac{2}{3}\right)^{k} \cdot 50
$$

for $k=6,7, \ldots$ In the limit, when $k \rightarrow \infty$, we get 0 .

So, at the end, we conclude that everyone should submit 0 .

What actually happened. The actual average of all the submissions was 13 .

To be more precise, the average was about 13 because the organizers decided to follow the rules of the contest and take into account all the submitted entries, including the ones that were clearly pranks - e.g., there were several clearly plank submissions of 100 or 99 . 
Such numbers cannot happen since the average of numbers between 0 and 100 cannot exceed 100 , and thus, $\frac{2}{3}$ of this average cannot exceed $\frac{2}{3}$ of 100 , i.e., the value

$$
\frac{2}{3} \cdot 100=66 \frac{2}{3}
$$

If we exclude such numbers, and only take into account serious answers - at least only answers which are smaller than or equal to $66 \frac{2}{3}-$ then the average becomes slightly smaller than 12 .

Problem. How can we explain this empirical result?

\section{Towards an Explanation}

Main idea. Some people are intuitive decision makers, some people are logical.

We do not know a priori how many people are more on the intuitive side, ad how many people are more on the logical side. In the first approximation, it is reasonable to assume that there are exactly the same number of intuitive and logical people.

What answer do we get under this assumption. Under the above assumption, half of the people would submit $33 \frac{1}{3}$, half would submit 0 , so the average is

$$
\frac{33 \frac{1}{3}+0}{2}=16 \frac{2}{3} \text {. }
$$

The $\frac{2}{3}$ of this average is

$$
\frac{2}{3} \cdot 16 \frac{2}{3}=11 \frac{1}{9}
$$

which is indeed very close to the desired answer of slightly smaller than 12 .

Why the difference. We made an assumption that there are exactly as many intuitive people and logical people, and came up with the answer of 11, slightly smaller than the actual value 12 .

The fact that the observed value is closer to the intuitive value than to the logical one means that, in general, there are slightly more intuitive people than logical ones. To be more precise, it means that people make intuitive decisions more frequently than logical ones - which seems to be in good accordance with the general spirit of Behavioral Economics; see, e.g., [2].

\section{Acknowledgments}

This work was supported in part by the US National Science Foundation grant HRD-1242122. 


\section{References}

[1] P. E. Tetlock and D. Gardner, Superforecasting: The Art and Science of Prediction, Broadway Books, New York, 2015.

[2] R. H. Thaler, Missbehaving: The Making of Bheavioral Economics, W. W. Notion, New York, 2015, 